\title{
Synchronous organics removal and copper reduction in semiconductor wastewater with energy recuperation via photocatalytic fuel cell
}

\author{
Sze-Mun Lam ${ }^{1, *}$, Man-Kit Choong ${ }^{1}$, Jin-Chung Sin $^{2}$ and Honghu Zeng ${ }^{3}$ \\ ${ }^{1}$ Department of Environmental Engineering, Faculty of Engineering and Green Technology, Universiti Tunku Abdul Rahman, Jalan \\ Universiti, Bandar Barat, 31900 Kampar, Perak, Malaysia \\ ${ }^{2}$ Department of Petrochemical Engineering, Faculty of Engineering and Green Technology, Universiti Tunku Abdul Rahman, Jalan \\ Universiti, Bandar Barat, 31900 Kampar, Perak, Malaysia \\ ${ }^{3}$ College of Environmental Science and Engineering, Guilin University of Technology, Guilin 541004, China
}

\begin{abstract}
An effective PFC constructed from $\mathrm{ZnO} / \mathrm{Zn}$ photoanode and carbon cloth cathode has been proposed to oxidatively degrade organics and reductively treat $\mathrm{Cu}$ (II) in the semiconductor wastewater accompanied with electricity production. The cell electrical performance with open circuit voltage of $835 \mathrm{~V}$, maximum power density of $0.003623 \mathrm{~mW} \mathrm{~cm}^{-2}$ and short circuit current density of $0.0506 \mathrm{~mA}$ $\mathrm{cm}^{-2}$ can be obtained using optimized catalyst loading of $1.0 \mathrm{~g} \mathrm{~L}^{-1}$ and semiconductor wastewater concentration of $10 \mathrm{mg} \mathrm{L}^{-1}$. Under the optimal test, more photogenerated electrons will be facilitated for charge carrier separation in the photoanode, accelerating the organics degradation on anode, and subsequently the electron migrating to cathode for $\mathrm{Cu}$ (II) reduction. A complete mineralization with 10 $\mathrm{mg} \mathrm{L}^{-1} \mathrm{COD}$ and more than $70 \% \mathrm{Cu}$ (II) removal efficiency can be attained within $180 \mathrm{~min}$. A good reproducibility test has been also witnessed because of the stable photoanode and cathode materials. This work may pave an effective and sustainable approach to concurrently eliminate two kinds of contaminants with energy recuperation in a single chamber.
\end{abstract}

\section{Introduction}

Semiconductor wastewater is one of the industrial water pollutions in Malaysia. Typically, this wastewater contained plenty kinds of harmful substances, such as cleaning agents, alkaline, cyanide, degreasing solvents as well as heavy metal ions including copper, zinc, and chromium [1]. These substances must be treated from the wastewaters prior to disposal due to they were considered toxic, persistent and bioaccumulative compounds.

Recently, a novel wastewater treatment technique, photocatalytic fuel cell (PFC) has demonstrated its salient feature in decomposing of organics and synchronously recuperated the chemical energy stored in wastewater [24]. In the PFC, semiconductor catalyst as a photoanode was photoexcited under light irradiation and formed electron-hole pairs. The holes with strong oxidizing ability can degrade the organics in the photoanode, while the electrons were transported to the cathode through external circuit and subsequently generated electricity. Through this method, the waste chemical energy in the organics can be recycled and reused with help of light energy. $\mathrm{ZnO}\left(E_{\mathrm{g}}=3.2 \mathrm{eV}\right)$ is a wide band gap semiconductor catalyst which attracted much interest of its promising chemical and physical, environmental stability and low cost characteristics. The $\mathrm{ZnO}$-based photocatalytic treatment has been reported as a highly effective method for the degradation of myriad recalcitrant organic and inorganic contaminants from industrial wastewaters $[5,6]$.

In this study, a multi-functional PFC utilizing $\mathrm{ZnO} / \mathrm{Zn}$ as a photoanode and carbon cloth as a cathode was constructed for removal of semiconductor wastewater-containing organics and $\mathrm{Cu}$ (II) with electricity production at the same time. various characterization techniques were also employed to study the structural and morphology properties of the synthesized $\mathrm{ZnO} / \mathrm{Zn}$. To the best of our knowledge, the PFC with two kinds of wastewater contaminants were eliminated and synchronously energy recuperation is scarcely reported and this study may pave an effective technique to real effluent treatment with concomitantly electricity harvesting.

\section{Experimental}

In a typical experiment, a $15.0 \mathrm{~cm} \times 2.0 \mathrm{~cm} \mathrm{Zn}$ foil was pre-treated by ultrasonic treatment in ethanol and followed by rinsing with distilled water. The suspension $\mathrm{ZnO}$ was prepared by adding $1.0 \mathrm{~g}$ of commercially available $\mathrm{ZnO}$ powder into $100 \mathrm{~cm}^{3}$ distilled water. The cleaned $\mathrm{Zn}$ foil was immersed in $\mathrm{ZnO}$ suspension and ultrasonicated for 1 hour. Subsequently, the $\mathrm{Zn}$ foil was

* Corresponding author: lamsm@utar.edu.my 
withdrawn from the suspension $\mathrm{ZnO}$ and dried in an oven at $90^{\circ} \mathrm{C}$ for 24 hours. Finally, the $\mathrm{ZnO}$ foil was calcined in furnace at $300^{\circ} \mathrm{C}$ for 2 hours.

The synthesized photoanode was characterized using an X-ray diffraction (XRD, Philips PW 1820) diffractometer, field emission-scanning electron microscope (FESEM, Quanta FEG 450) coupled with energy dispersive X-ray spectroscopy (EDX) and Fourier transform infrared (FTIR, Spectrum RX 1) spectrometer.

A PFC with a $\mathrm{ZnO} / \mathrm{Zn}$ photoanode and a carbon cloth cathode was constructed. Light exposure area of both electrodes was $6 \mathrm{~cm}^{2}$ and the photoelectrodes was set at a distance of $5 \mathrm{~cm}$. The $\mathrm{ZnO} / \mathrm{Zn}$ photoanode was irradiated by a $365 \mathrm{~nm}$ mercury UV lamp (UVP Pen-Ray, light intensity of $1255 \mu \mathrm{W} \mathrm{cm} \mathrm{cm}^{-2}$ ). An aerated pump was applied to provide air bubbling with flow rate of $2 \mathrm{~L} \mathrm{~min}^{-}$ ${ }^{1}$ near the photocathode. In a typical experiment, the PFC was conducted in a beaker filled with $400 \mathrm{~mL}$ of real semiconductor wastewater. Raw wastewater used in this study collected from a semiconductor manufacturing company located at Penang state. Schematic diagram of the PFC experiment setup is shown in Fig. 1. The voltage production in this work was measured with a digital multimeter (Brother Big Display Digital Multimeter HD517, Japan). Chemical oxygen demand (COD) was tested using Hach $\mathrm{COD}$ vials, and the $\mathrm{Cu}$ (II) concentration was analyzed using a Varian Vista Pro inductively coupled plasma-optical emission spectrometry (ICP-OES).

\section{Results and discussion}

\subsection{Characteristics of photoanode}

Fig. 2a shows the XRD pattern of the $\mathrm{ZnO} / \mathrm{Zn}$ photoanode. It was observed that the samples exhibited the typical character of wurtzite hexagonal phase structure based on the JCPDS No. 36-1451 [2]. The detected $\mathrm{Zn}$ peaks were associated to the $\mathrm{Zn}$ substrate. The sharp and strong diffraction peaks demonstrated the samples obtained were in a good crystalline form. No other impurity peaks were identified in the pattern, inferring the phase purity of the $\mathrm{ZnO}$ and $\mathrm{Zn}$. The microscopic analysis of the $\mathrm{ZnO} / \mathrm{Zn}$ photoanode is displayed in Fig. 2b. It was found that $\mathrm{ZnO}$ particles to be tetragonal and rod-like morphology with sizes in the range from 70 to $710 \mathrm{~nm}$ and they were homogenously distributed on $\mathrm{Zn}$ foil. Using EDX analysis, the elements such as $\mathrm{Zn}$ and $\mathrm{O}$ can be visibly seen in the sample as indicated in Fig. 2c. The findings witnessed the presence of $\mathrm{ZnO}$ elements on the $\mathrm{Zn}$ film.

Fig. 2d depicts the FTIR spectrum of $\mathrm{ZnO} / \mathrm{Zn}$ photoanode. The dominant absorption peaks identified at the regions $500-535 \mathrm{~cm}^{-1}$ could be ascribed to the to the stretching and bending vibration of $\mathrm{OH}^{-}$groups, respectively. This due to a small amount of absorbed $\mathrm{H}_{2} \mathrm{O}$ stretching vibration of $\mathrm{Zn}-\mathrm{O}$ bond. The broad absorption peak found $3500 \mathrm{~cm}^{-1}$ and $1630 \mathrm{~cm}^{-1}$ could be attributed molecules bound on the photoanode surface [7]. The presence of $\mathrm{OH}^{-}$groups on the photoanode was beneficial to the activity as they might form a highly oxidative $\cdot \mathrm{OH}$ radicals with the positive hole.

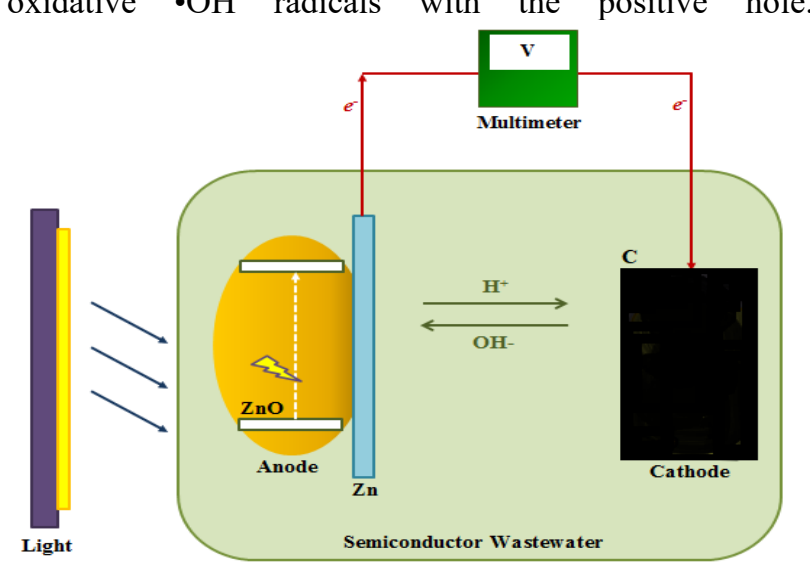

Fig. 1. Schematic diagram of PFC experimental setup.

\subsection{Factors influencing the cell electric performance}

Influences of the catalyst loading and initial semiconductor wastewater concentration on the cell electric performance were evaluated to obtain the best PFC condition. Figs. $3 a$ and $b$ exhibits that the cell performance demonstrated to be strongly dependent to the catalyst loading, power density $\left(P_{\max }\right)$ increased quickly from $0.00223 \mathrm{~mW} \mathrm{~cm}^{-2}$ at $0.2 \mathrm{~g} \mathrm{~L}^{-1}$ to 0.003623 $\mathrm{mW} \mathrm{cm}{ }^{-2}$ at $1.0 \mathrm{~g} \mathrm{~L}^{-1}$. Similarly, the open circuit voltage $\left(V_{\mathrm{oc}}\right)$ increased from $656 \mathrm{~V}$ to $835 \mathrm{~V}$ with increasing the catalyst loading. Nevertheless, the $P_{\max }$ decreased from $0.0034 \mathrm{~mW} \mathrm{~cm}^{-2}$ to $0.00291 \mathrm{~mW} \mathrm{~cm}^{2}$ at higher catalyst loading of $1.5 \mathrm{~g} \mathrm{~L} \mathrm{~L}^{-1}$ and $2.0 \mathrm{~g} \mathrm{~L}^{-1}$, respectively.
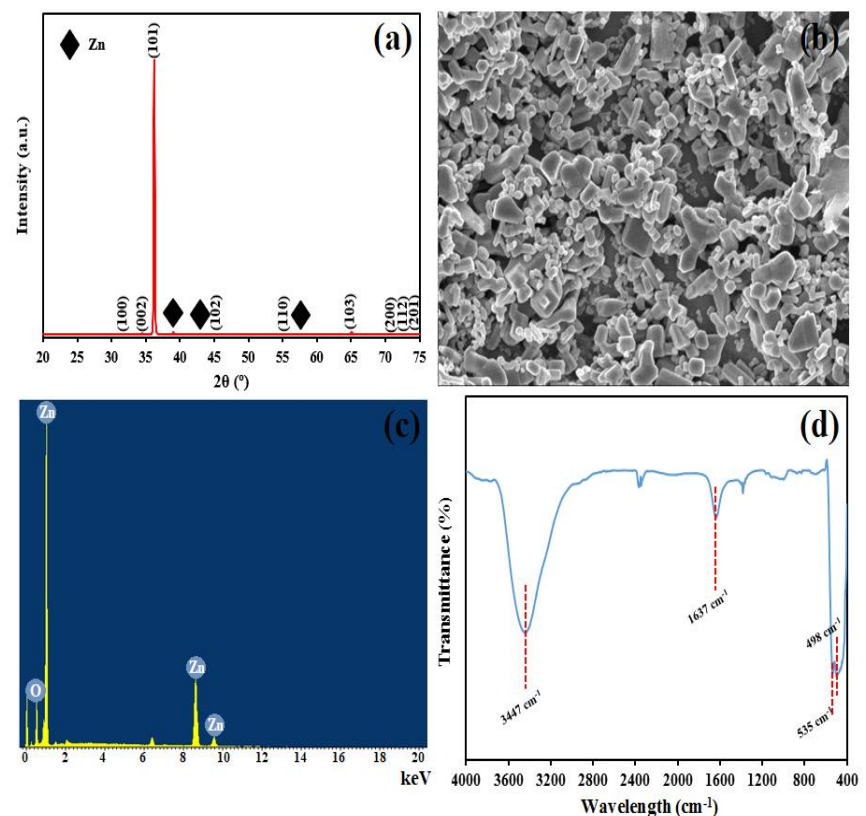

Fig. 2. (a) XRD spectrum, (b) FESEM image, (c) EDX spectrum, and (d) FTIR spectrum of $\mathrm{ZnO} / \mathrm{Zn}$ photoanode. 

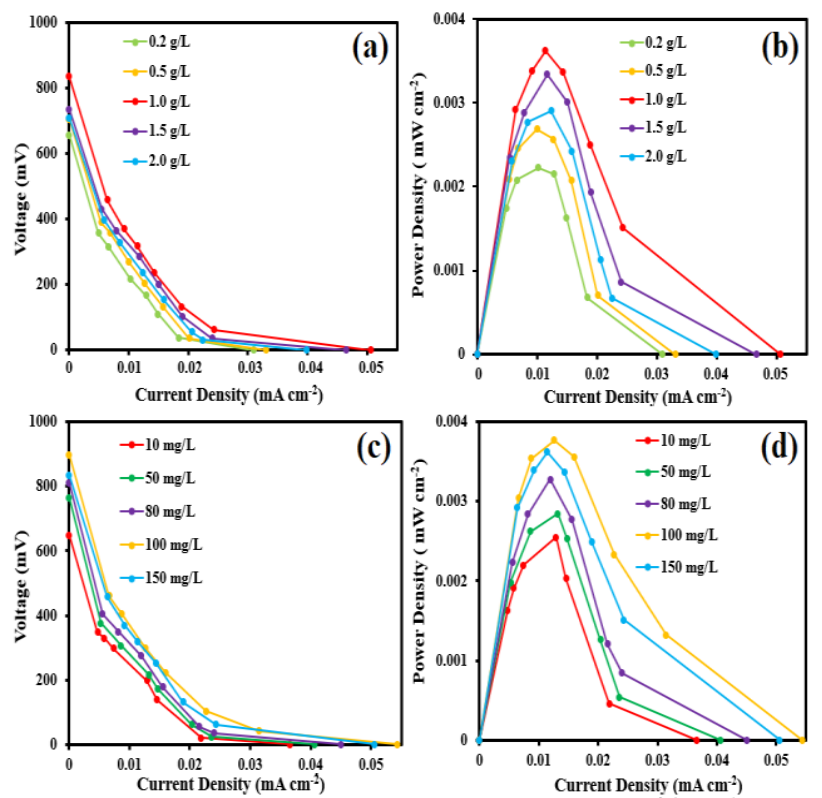

Fig. 3. (a) Polarization, (b) power curves for with various $\mathrm{ZnO}$ loadings, (c) polarization, (d) power curves for with various semiconductor wastewater concentrations in the PFC.

The $V_{\text {oc }}$ also declined from $735 \mathrm{~V}$ and $708 \mathrm{~V}$ with increasing the catalyst loading. Higher amount of catalyst revealed more availability of total surface area and active sites of the catalyst. This phenomenon provided more photogenerated electrons to channel from photoanode to cathode via external circuit, and thereby yielded high electrical power. Conversely, a reduction in electricity performance might be owing to aggregation of $\mathrm{ZnO}$ particles in the thin film restricted of mass transfer between the photogenerated electrons and catalyst [8], as also demonstrated by short circuit current density $\left(J_{\mathrm{SC}}\right)$ in Fig. 3b. Hence, the cell performance is highly sensitive on the catalyst loading and the optimal catalyst loading to attain the maximum $P_{\max }, V_{\mathrm{OC}}$ and $J_{\mathrm{SC}}$ values was $1.0 \mathrm{~g} \mathrm{~L}^{-}$ 1

Figs. $3 \mathrm{c}$ and $\mathrm{d}$ shows the cell performance as a function of initial semiconductor wastewater concentration at $1.0 \mathrm{~g} \mathrm{~L}^{-1}$ catalyst loading. As indicated in the figures, the $P_{\max }, V_{\mathrm{OC}}$ and $J_{\mathrm{SC}}$ linearly improved, when the initial semiconductor concentration raised from 10 to $150 \mathrm{mg} \mathrm{L}^{-1}$, which could be due to higher semiconductor wastewater concentration could decrease the light penetration to photoanode. Another reason which may be resulted for the drop in the performance was the increased in the semiconductor wastewater concentration seem to reduce the occupancy of pollutants on the catalyst active sites. Consequently, the initial semiconductor wastewater of $10 \mathrm{mg} \mathrm{L}^{-1}$ was an ideal concentration in the cell performance.

The PFC for synchronously COD degradation and $\mathrm{Cu}$ (II) reduction was investigated with catalyst loading at $1.0 \mathrm{~g} \mathrm{~L}^{-1}$ and $10 \mathrm{mg} \mathrm{L}^{-1}$ semiconductor wastewater concentration. Removal of $\mathrm{Cu}$ (II) from semiconductor wastewater should be surmounted to preserve the aquatic environment, including surface water quality. The toxicity of $\mathrm{Cu}$ (II) to freshwater aquatic organisms can even be found at low concentration levels of $28-172 \mu \mathrm{g}$ $\mathrm{L}^{-1}[9]$.

\subsection{Synchronous removal efficiency of pollutants and reusability}

Fig. 4 presents that the cell displayed almost no COD removal and $\mathrm{Cu}$ (II) reduction in the dark condition, indicating that the semiconductor wastewater was very stable in the absence of light. Conversely, under the exposure of light, a complete COD removal was achieved after $180 \mathrm{~min}$. This suggested that charge carrier separation in photoanode was highly stimulated by the light-PFC reaction. Moreover, the $\mathrm{Cu}$ (II) removal efficiency was $70 \%$ under the similar condition. This phenomenon implied that the photogenerated electrons transported to the cathode involved in $\mathrm{Cu}$ (II) reduction, and some electrons were most likely been partook in oxygen reduction reaction in the semiconductor wastewater $[10,11]$. In addition, no substantial drop was observed for concurrent COD removal efficiencies of both organics in semiconductor wastewater and $\mathrm{Cu}$ (II) after three recycling runs due to the stable $\mathrm{ZnO} / \mathrm{Zn}$ photoanode and carbon cloth cathode materials. Thus, efficient removal of both organics and $\mathrm{Cu}$ (II) with synchronously electricity production can been obtained in this multi-functional and stable PFC device, demonstrating a tantalizing prospect of application and spreading.
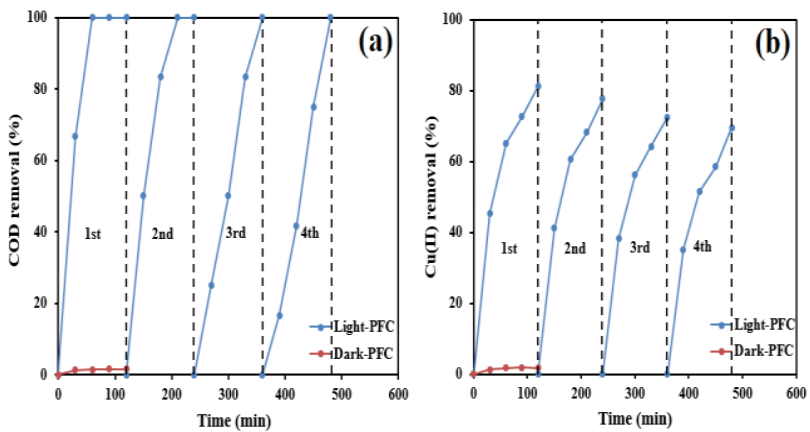

Fig. 4. Concurrent elimination of (a) $\mathrm{COD}$ and (b) $\mathrm{Cu}$ (II) in the $\mathrm{PFC}$ in the presence of four light operated runs and dark condition in semiconductor wastewater.

\section{Conclusions}

A photocatalytic fuel cell for both removal of organics and $\mathrm{Cu}$ (II) and synchronously electricity production has been successfully constructed in this study. The physicochemical property of as-fabricated $\mathrm{ZnO} / \mathrm{Zn}$ photoanode has been analyzed by various characterization techniques. The cell electric performance was affected by catalyst loading and semiconductor wastewater concentration. With the catalyst loading of $1.0 \mathrm{~g} \mathrm{~L}^{-1}$ and semiconductor wastewater concentration of $10 \mathrm{mg} \mathrm{L}^{-1}$, the optimal device can achieve a $V_{\mathrm{OC}}$ of $835 \mathrm{~V}$, a $P_{\max }$ of 0.003623 $\mathrm{mW} \mathrm{cm} \mathrm{cm}^{-2}$ and a $J_{\mathrm{SC}}$ of $0.0506 \mathrm{~mA} \mathrm{~cm}^{-2}$. For the pollutant

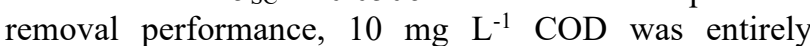
mineralized and more than $70 \%$ removal efficiency can be attained within $180 \mathrm{~min}$. The reason of cell 
enhancement could be due to the electron transported to the cathode can be used for the $\mathrm{Cu}$ (II) reduction. This work may pave an alternative way for an innovative and sustainable approach for removal of organic pollutant and heavy metal ion in the wastewater with concomitant electricity generation in a single chamber PFC.

The research was supported by Universiti Tunku Abdul Rahman (UTARRF/2019-C1/L03), Ministry of Higher Education of Malaysia (FRGS/1/2016/TK02/UTAR/02/1 and FRGS/1/2019/TK02/UTAR/02/4), The Guangxi Key Laboratory of Theory and Technology for Environmental Pollution Control, China (1801K012 and 1801K013), and L'Oréal-UNESCO Research Fund.

\section{References}

1. M. Al-Shannag, K. Bani-Melhem, Z. Al-Anber, Z. Al-Qodah, Sep. Sci. Technol. 48, 673 (2013)

2. M.W. Kee, J.W. Soo, S.M. Lam, J.C. Sin, A.R. Mohamed. J. Environ. Manage. 228, 383 (2018)

3. Y. Ye, H. Bruning, X.L. Li, D. Yntema, H.H.M. Rijnaarts, Chem. Eng. J. 354, 553 (2018)
4. S. Xie, K. Ouyang, J. Colloid Inter. Sci. 500, 220 (2017)

5. S.M. Lam, J.A. Quek, J.C. Sin. Mater. Lett. 195, 34 (2017)

6. A.A. El-Bindary, S.M. El-Marsafy, A.A. El-Maddah, J. Mol. Struct. 1191, 76 (2019)

7. H. Vahdat Vasei, S.M. Masoudpanah, M. Adeli, M.R. Aboutalebi, Adv. Powder Technol. 30, 284 (2019)

8. S. Kaneco, H. Katsumata, T. Suzuki, K. Funasaka, K. Ohta, K. Bull. Catal. Soc. India, 6, 22 (2007)

9. R.C. Santore, D.M. Di Toro, P.R. Paquin, H.E. Allen, J.S. Meyer, Environ. Toxicol. Chem. 20, 2397 (2001)

10. K. Wan, Z.P. Yu, X.H. Li, M.Y. Liu, G. Yang, J.H. Piao, Z.X. Liang, ACS Catal. 5, 4325 (2015)

11. B. Wang, H. Zhang, X.Y. Lu, J. Xuan, M.K. Leung, Chem. Eng. J. 253, 174 (2014). 